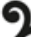

\title{
METODOLOGIA DO DESIGN PARA WEB: UMA PROPOSTA DE UNIFICAÇÃO DAS METODOLOGIAS PROJETO E E SCRUM
}

Luiza Grabriela Ribeiro Dantas

Fundação Centro de Análise, Pesquisa e Inovação Tecnológica - FUCAPI

luiza.dantas@live.com

Andressa Maria Cruz dos Santos

Fundação Centro de Análise, Pesquisa e Inovação Tecnológica

Andressa.santos@fucapi.br

Resumo: As Instituições de Ensino Superior geralmente trabalham em consonância com as exigências do mercado de trabalho. Metodologias, literatura e forma de abordagem exploradas na academia são motivadas pelas novidades, tendências e novos estudos. Dentro dessa perspectiva, este artigo tinha a intenção de apenas apresentar as metodologias do Design para Web ensinadas na academia e compara-las com as exploradas pelo mercado. Porém, os caminhos pesquisados guiou-nos para a inserção de um novo desafio que foi propor a unificação das metodologias Projeto E e Scrum para projetos voltados para Web. Justificamos a proposta de unificação de metodologias com o ato de contribuir com a prática de projetos em Web Design tanto no âmbito acadêmico quanto profissional.

Palavras-chave: Web Design, Metodologia, Projeto E, Scrum.

Abstract: Higher education institutions usually work in line with the requirements of the labor market. Methodologies, literature and way of approach explored in the academy are motivated by the news, trends and new studies. From this perspective, this article was intended to show only the methodologies of design for Web taught in academia and compares them with those exploited by the market. However, the surveyed paths led us to the inclusion of a new challenge that was proposing the unification of methodologies Project $E$ and Scrum for projects for the Web. We justify the proposed unification of methodologies with the act of contributing to the project practice web Design in both academic and professional level.

Keywords: Web Design, Methodology, Project E, Scrum. 


\section{INTRODUÇÃO}

O design apresenta algumas particularidades em seu desenvolvimento, seja no âmbito acadêmico ou profissional. Uma das particulares que merece destaque é o Procedimento Metodológico em Design o qual, junto à metodologia da pesquisa científica, se materializa num resultado acadêmico e, em consonância aos demais métodos, técnicas e ferramentas do design se consolida em resultados digitais (ou não) no mercado de trabalho.

No mercado de Web Design, os projetos são desenvolvidos com métodos específicos e a sua escolha dá-se por afinidade, natureza do projeto, habilidades e conhecimentos que integrantes do projeto possui (design gráfico, ilustrador, UX, UI, desenvolvedor front-end e outros). Tais informações foram levantadas através de um questionário aplicado na comunidade acadêmica e profissional ${ }^{1}$ do design visando detectar quem apresenta foco em web e quais metodologias mais utilizam.

Com base no exposto, o presente artigo apresenta primeiramente a análise das metodologias Projeto E e Scrum que, segundo o resultado do questionário, são as mais utilizadas em projetos em design voltados para a web; posteriormente a descrição dos pontos que se assemelham ou se diferenciam e a sugestão de uma forma em que ambas possam ser aplicadas unificadas dando ênfase ao que cada uma apresenta de melhor.

Segundo Meurer \& Szabluk (2012), a metodologia Projeto E surgiu para guiar e otimizar o desenvolvimento de projetos de interface gráfica amigável para diferentes sistemas e produtos interativos dígito-virtuais. E não sendo sequencial, permite que a reorganização de processos seja de acordo com a complexidade do projeto podendo assim alterar ou omitir alguns processos. O Scrum, por sua vez, tem como fundamento "controlar processos empíricos, mantendo o foco na entrega de valor de um negócio em menor tempo possível" (CRUZ, 2013, p.31). Ou seja, duas metodologias com focos distintos e que se complementam. Nessa perspectiva, justifica-se essa proposta de unificação de metodologias visando contribuir com a prática de projetos em Web Design tanto no âmbito acadêmico quanto profissional.

\section{DESENVOLVIMENTO}

\subsection{WEB DESIGN}

"Design é a atividade científica de projetar" que envolve diversas áreas do conhecimento e integra relações múltiplas de solução de problemas de produção de objetos que se destinam a atender as necessidades do homem e da comunidade (NIEMEYER, 2000, p. 23); ou seja, é um meio de facilitar o uso de um produto, serviço ou processo melhorando e aperfeiçoado a estética, forma, e função além de solucionar problemas e atender as necessidades dos usuários ao promover o seu conforto e a sua satisfação pessoal.

Segundo Schneider (2010, p. 197), "Design é a visualização criativa e sistemática dos processos de interação e das mensagens de diferentes atores sociais" que facilitam o envolvimento com profissionais de áreas afins.

É dentro da perspectiva da multidisciplinaridade do design que o Web design se insere, pois segundo Gomes Filho (2006) ele está enquadrado no Design Gráfico e

\footnotetext{
${ }^{1}$ Comunidade acadêmica e profissional de Design de algumas faculdades de Manaus - AM.
} 
analisa as condicionantes relacionadas com sistemas gráficos ou visuais, na relação com o homem e a informação e na composição de sites, home pages, projetos multimídia e outros.

\subsection{PROJETO E E SCRUM}

As metodologias Projeto E e Scrum foram as mais citadas como referência (conhecimentos teóricos e práticos) no questionário aplicado a designers da cidade de Manaus. Para fazer um comparativo de suas respectivas fases e pontos positivos e negativos, fez-se necessário um levantamento bibliográfico exposto a seguir:

\subsection{Analisando o Projeto $E$}

O desenvolvimento de interfaces tornou-se multidisciplinar. É por meio da interface que o usuário se comunica para realizar as tarefas desejadas e por isso ela é parte fundamental do sistema. O Projeto E surgiu a partir da necessidade de definir com clareza e objetividade uma metodologia projetual para guiar e otimizar o desenvolvimento de projetos de interface gráfica amigável para diferentes sistemas e produtos interativos dígito-virtuais. (MEURER; SZABLUK, 2012)

Segundo Meurer e Szabluk (2011), taxonomia é uma forma de criar foco no produto e auxiliar os alunos a situá-lo em um contexto maior, considerando suas funcionalidades e a forma como será utilizado. O Projeto E apresenta como características de um produto dígito-virtual as seguintes taxonomias: necessidade, oportunidade, finalidade, atuação, plataforma e tecnologia. Onde, necessidades trata quais as mudanças, intervenções ou criações dentro do projeto. Oportunidade define qual a tecnológica: se intelectual ou física. Finalidade de otimização, administração e informação. Atuação no sentido de qual intenção o projeto será desenvolvido, se é por uma causa social, institucional ou de serviços. Plataforma para a definição de onde irá ser acessado, como irá ser transmitido (celular, computadores desktop, tamanhos de display). E, Tecnologia, ou seja, linguagens de programação, de marcação e de armazenamento de dados.

O Projeto E possui referências de que são subdivididas por categorias em temas dentro de cada uma delas. Por ordem temos a Contextualização do projeto onde há temas como situação inicial bem definida e situação final bem definida, questões projetuais, taxonomia. Definição de papéis, condição atual e condição pretendida. Identificação dos usuários, definição de personas, equalização dos fatores projetuais e definição do foco das pesquisas e análises. Em segundo, temos a categoria de Desconstrução que possui os temas termos pertinentes ao projeto, linha do tempo, similares e referências, estruturas morfológicas, funcionais e heurísticas, comparativa de funcionalidades, da identidade gráfico-visual, teste de resposta emocional, focus group (grupos focais). Verificação onde há uma análise dos processos já realizados. Reconstrução com os temas definição das ferramentas, funcionalidades e conteúdo, cenário hipotético, storyboard, wireframes e casos de uso. Identidade com editoração e diagramação, definição de assinatura visual, tipografia, definição imagética e da matriz cromática. Diferenciação, Desenvolvimento e Validação. Essas etapas foram condensadas nos "E's" no nome da metodologia projetual, conforme figura $1 \mathrm{e}$ descrições a seguir: 


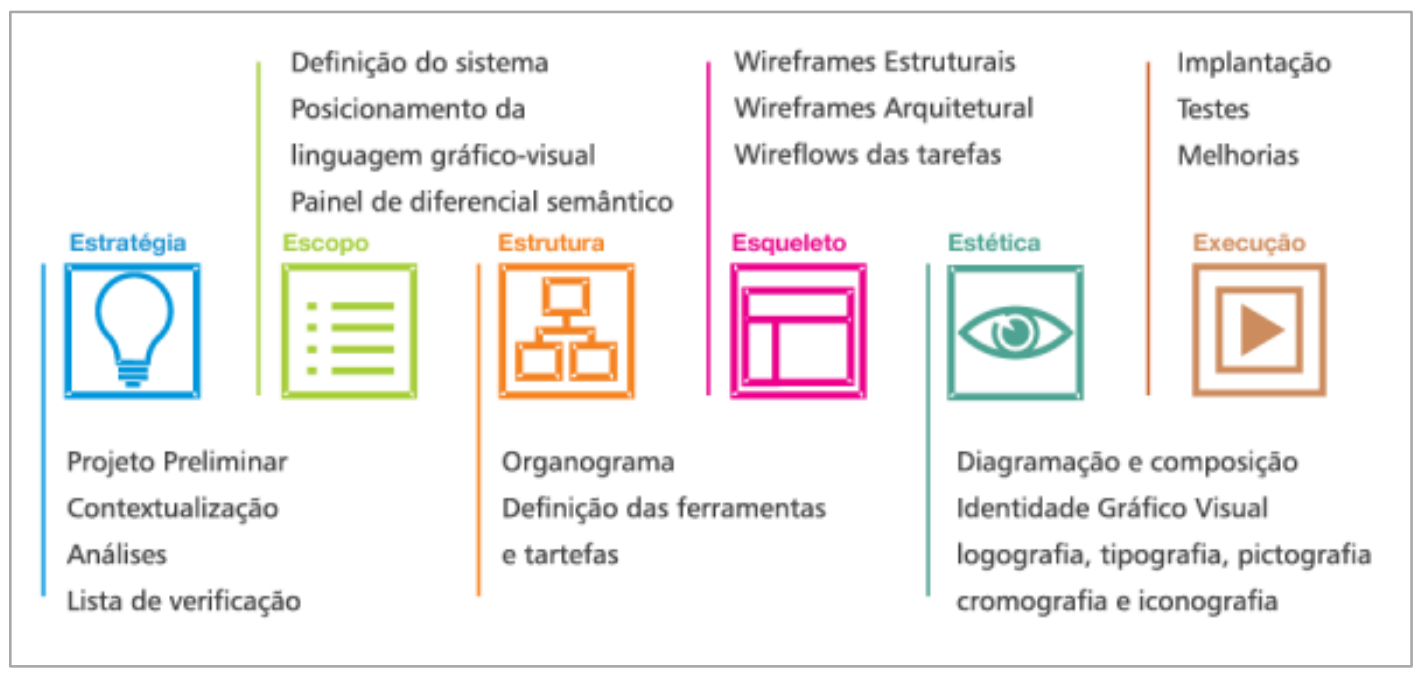

Figura 1 - Etapas do projeto $\mathrm{E}$

Fonte: MEURER; SZABLUK, 2012.

$\mathrm{Na}$ fase Estratégia, há uma identificação do projeto para se saber o que é o projeto. Posteriormente uma contextualização geral onde se faz a análise deste projeto, no que gera uma lista de verificações tais como a taxonomia. Esta fase é fundamental para o decorrer do projeto. Na fase Escopo se inicia a arquitetura de informação que o projeto deve conter, linguagem gráfico-visual, estrutura de informações classificadas com hierarquia, relações entre o processo de cada informação com um painel semântico. Na fase Estrutura ocorre a interação do produto por meio de ilustrações, as alternativas diversas para chegar a um modelo em que a experiência do usuário seja satisfatória. Definição de tarefas dos usuários, regras, quais permissões ele pode ter acesso em seu produto. No Esqueleto ocorre a geração de alternativas da estrutura do projeto em wireframes. Nesta fase os testes de usabilidade e acessibilidade já devem ser considerados. Em Estética é gerado o layout com a diagramação por meio de grids, composições da identidade gráfico-visual: logografia, cronografia, tipografia, pictografia e iconografia. O esqueleto começa a ganhar mais vida e seu visual fica mais robusto. E, na fase Execução que é a fase de encerramento de todo o desenvolvimento partindo para a implantação das técnicas aplicadas por meio de teste com o usuário ocorrem alterações de acordo com o cliente e com o usuário. Onde um modelo funcional estará exposto para essas conclusões a fim de descobrir onde mais o projeto pode melhorar.

Apesar de cada fase apresentar funções bem definidas, "todas as etapas do Projeto E - com exceção da Estratégia, primeira etapa do processo - incluem possíveis gerações de alternativas." (MEURER; SZABLUK, 2012). A metodologia projetual "Projeto E" não é sequencial e permite que a reorganização de processos de acordo com a complexidade do projeto, podendo alterar e omitir alguns processos, bem como trabalhar com apenas duas etapas para o projeto.

\subsubsection{ANALISANDO O SCRUM}

O termo Scrum surgiu do Rugby. No jogo, a palavra scrum descreve a formação ordenada dos jogadores em determinados momentos da partida. A inspiração aqui vem da união que equipes esportivas necessitam para vencer o jogo. (GUERRATO, 2013). Sua ideia principal é controlar processos empíricos, mantendo o foco na entrega de valor de um negócio em menor tem possível. (CRUZ, 2013, p.31) 
A teoria do Scrum emprega uma abordagem iterativa e incremental para otimizar a previsibilidade e controlar riscos (SCHWABER, 2009). Três pilares sustentam qualquer implementação de controle de processos empíricos do Scrum que fundamentam sua teoria: transparência, inspeção e adaptação.

No item transparência, garante-se que os aspectos do processo que afetam o resultado sejam visíveis e conhecidos aos que controlam o resultado, ou seja, quando alguém inspeciona o resultado e dá como pronto, isso deve ser equivalente à definição de pronto utilizada. Em inspeção, os processos devem ser totalmente inspecionados com frequência e suficiente para que as variações possam ser detectadas. Cabe aqui destacar que o processo pode ser modificado pelo próprio ato de inspecionar. Em adaptação, o processo ou material produzido deverá ser ajustado o mais rápido possível para que os desvios futuros sejam minimizados, isso como consequência de inspeção caso tenha sido determinada uma variação de fora dos limites aceitáveis em um ou mais aspectos do processo, e que o produto resultante será inaceitável. (CRUZ, 2013)

Papéis e responsabilidade são bem definidos no Scrum: o Scrummaster que é o responsável maior do projeto que garante que o processo de união e entendimento da equipe seja entendido e seguido por todos. O Product Owner que visa maximizar o valor do trabalho que o Time Scrum faz. E o Time que é quem executa o trabalho propriamente dito. "É o time de desenvolvedores responsáveis por transformar o Backlog do Produto em incrementos e funcionalidades que possam ser entregues aos clientes" (CRUZ, 2013).

Visando um "controle de qualidade", o Scrum apresenta também os requisitos do produto a ser entregue, bem como todo o entendimento necessário para atender aos requisitos, produzir funcionalidades ou produtos, e por fim, entregar o produto. Esse processo de atribuir tais requisitos, chama-se backlog e é o principal artefato do Scrum (CRUZ, 2013). Dentro dessa perspectiva, Reunião de Planejamento da Versão para Entrega; Sprint; Reunião de Planejamento da Sprint; Revisão da Sprint; Retrospectiva da Sprint e Reunião Diária são eventos de duração fixa chamados de time-boxed. Dentre eles, destaca-se a Sprint por ser uma iteração. Durante a Sprint, o ScrumMaster garante que não será feita nenhuma mudança que possa afetar a Meta da Sprint. Tanto a composição do time quanto as metas de qualidade devem permanecer constantes durante a Sprint (SCHWABER, 2009).

\section{PROCEDIMENTOS METODOLÓGICOS}

O presente artigo iniciou-se com a consolidação da fundamentação teórica com base nas pesquisas bibliográficas e documentais. Em seguida, uma pesquisa exploratória e de campo através do instrumento questionário (pesquisa telematizada pesquisa em internet) para levantamento das metodologias mais utilizadas no meio acadêmico e profissional referente aos projetos dígito-virtuais, conforme Gráfico $1 \mathrm{a}$ seguir: 
Gráfico 1 - Metodologia de interesse de universitários de Design em Manaus-AM

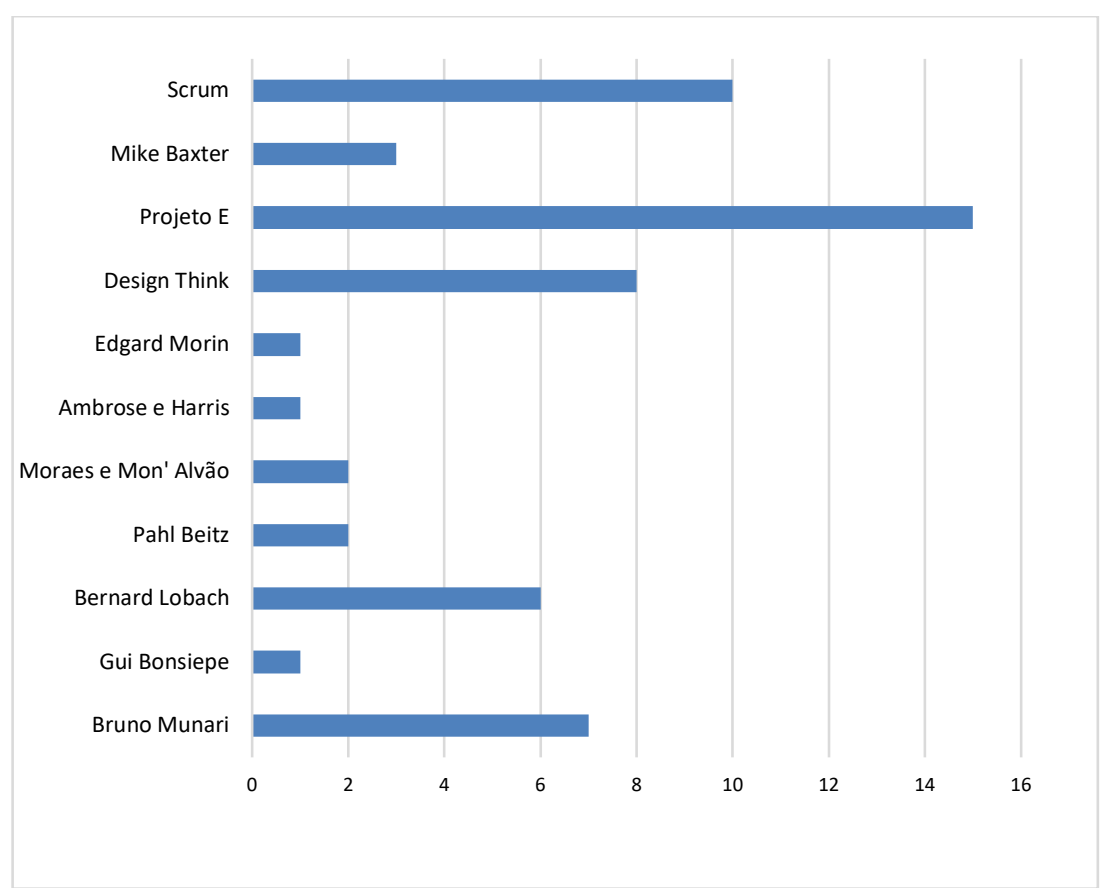

Fonte: Elaborado pela autora, com base na pesquisa realizada.

A metodologia projetual aplicada no processo de desenvolvimento do questionário foi linear na qual primeiro ocorreu a definição do objetivo que é analisar as metodologias - utilizadas em projetos em design voltados para a web - mais citadas no questionário (Projeto E e Scrum); conhecer os processos de como estes utilizam cada metodologia; citar em quais pontos se assemelham ou se diferenciam e sugerir uma forma em que possam ser aplicadas de forma unificada dando ênfase ao que cada uma apresenta de melhor; Em seguida definiu-se a estratégia para aplicar questionário através da plataforma de formulários do Google Forms. Para tanto, fez-se uso de um Brainstorming para a elaboração das perguntas; com os dados inseridos na plataforma de formulários, realizou-se um pré-teste do questionário, visando a correção de pontos em duplicidade ou com difícil interpretação. Finalizando e após as devidas correções o questionário foi devidamente aplicado e seus resultados foram apresentados através de gráficos para maioria das questões.

Visando construir o referencial teórico acerca do tema explorado neste artigo, buscaram-se, através da pesquisa bibliográfica, autores e suas obras relativas ao Processo Metodológico de Design para Web com foco nas metodologias Projeto E e Scrum. A pesquisa bibliográfica referida foi realizada em livros e artigo sobre a temática central visando a análise crítica em conteúdos literários de caráter científico pertinentes.

Com 6 questões abertas e fechadas, o questionário foi apresentado à comunidade acadêmica e profissional de design. O objetivo central foi detectar quais trabalham direta ou indiretamente com Web. Uma vez detectado, optou-se por realizar uma entrevista semiestruturada a fim de registrar eventuais particularidades durante a prática das Metodologias Projeto E e Scrum em seus respectivos locais de trabalho ou de desenvolvimento de projetos. 


\subsection{SOBRE A ENTREVISTA}

A entrevista foi realizada com 10 pessoas que trabalham com projetos dígitovirtuais, escolhidas com base nas respostas do questionário. A entrevista foi feita por meio de conversas pelas redes sociais e por telefone. Onde fizeram-se as seguintes perguntas: "Qual a sua função no projeto? ", "Como você "passa" ou "recebe" os processos do projeto para alguém? ", "Você possui conhecimento amplo do objetivo do projeto?", "Como você se organiza para entregar os arquivos solicitados? ", "Você deixa visível cada execução de suas tarefas para todos os membros do projeto? " e "Você tem voz no projeto? (Há transparência de ideias e opiniões)".

O critério da elaboração das perguntas foi com o objetivo de conhecer indiretamente quais os processos são utilizados no meio de desenvolvimento de projetos no espaço profissional. A análise foi feita nas respostas repetidas ou, em citações únicas.

\subsubsection{RESULTADOS DA ENTREVISTA}

Perguntado sobre a função que exerce no projeto web, 1 pessoa respondeu que possui várias funções no projeto. Outras 5 pessoas atuam com 2 funções no projeto e 4 pessoas relataram que possuem 1 função.

"Tenho companhar, gerir e desenvolver a criação de gráficos, interface, arquitetura de informação e até parte de programação."

"Desenvolver o visual do projeto, e dependendo do projeto, a experiência do usuário." "Sou UX Designer (Pesquiso e aplico métodos e técnicas para colher insights que irão guiar as decisões do projeto) e UI (User Interface, ou seja, faço os layouts dos projetos)"

A respeito de como são repassados os entregáveis do projeto, 5 pessoas responderam que trabalham com o conceito do Scrum. Alguns relataram o uso de sistemas on-line para garantir que todos tenham acesso ao painel onde se encontram o backlog e checklist de todo o projeto. 3 pessoas realizam entregas via e-mail 2 pessoas via compartilhamento na nuvem.

Com objetivo do projeto 7 pessoas afirmaram ter sempre o conhecimento do objetivo amplo do projeto, 2 pessoas responderam que depende de quem é o responsável pelo projeto e 1 pessoa respondeu que não tem conhecimento do objetivo do projeto.

Para 6 pessoas a organização para a entrega é baseada em sprints, 1 pessoa utiliza o método kanban e 3 pessoas possuem seu próprio método baseado em estimativa e prioridade de entrega.

Em relação a deixar visível o estado de suas responsabilidades para outros membros do projeto 1 pessoas responderam que não deixam à mostra suas atividades e 9 deixam claro para todos o que estão fazendo.

Todas as 10 pessoas afirmaram que possuem voz no projeto a fim de impactar em mudanças de andamento do projeto. Nem sempre as ideias são acatadas, mas há sempre transparência de ideias que surgem durante o desenvolvimento do projeto. 


\subsection{COMPARAÇÃO PROJETO E E SCRUM}

As características de cada metodologia visam extrair ao máximo a modelagem das etapas que um projeto pode possuir. O Projeto E possui 6 etapas bem específicas, no entanto não são todas realizadas. Quanto ao mercado de trabalho, nem o Projeto $\mathrm{E} e$ nem suas etapas em separado foram citadas (ver gráfico 3). No entanto, nas referências acadêmicas, a metodologia foi selecionada como a mais completa para se inspirar e desenvolver como observado no gráfico 2 .

\section{Gráfico 2 - referências acerca de procedimentos metodológicos enquanto universitário}

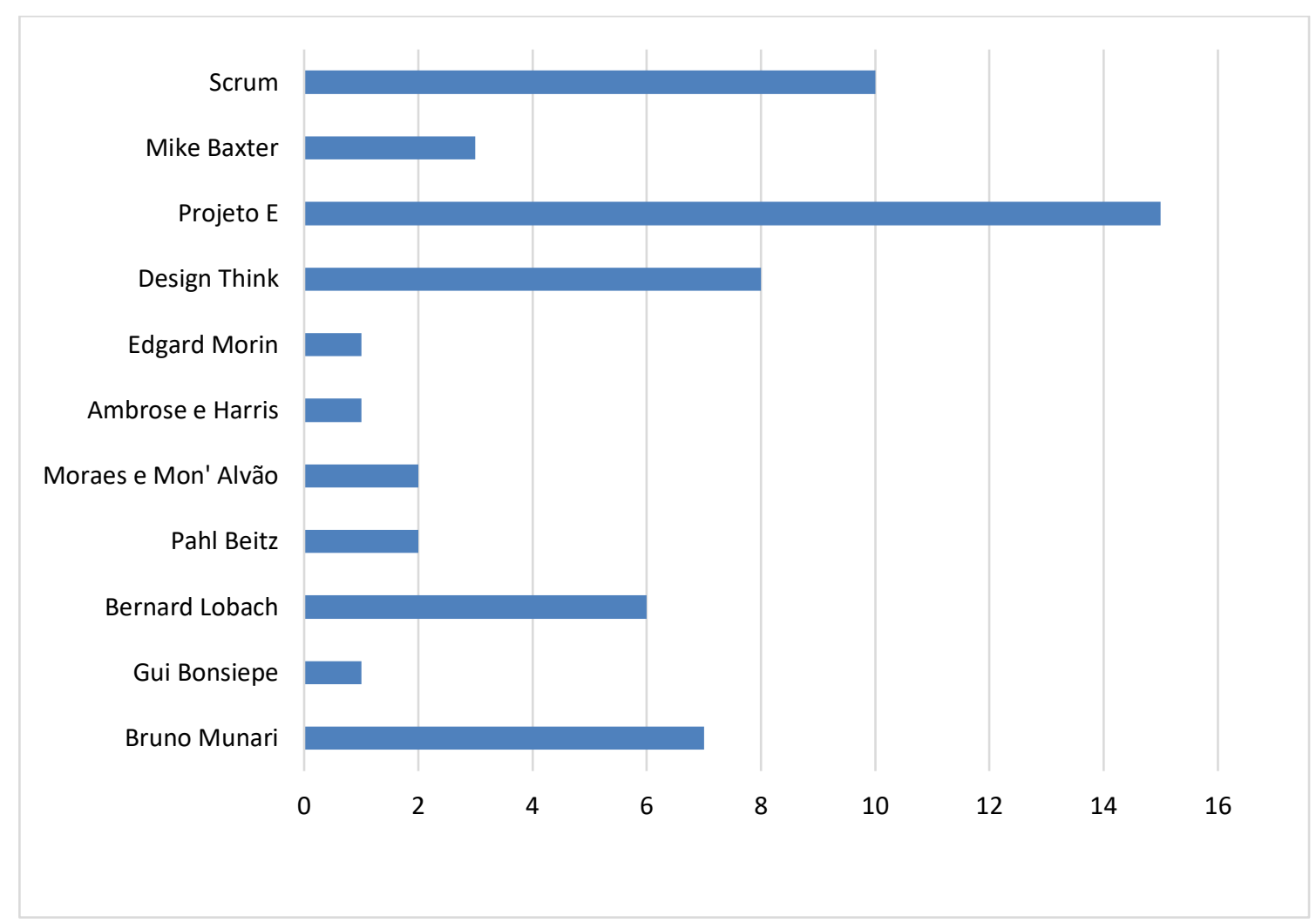

Fonte: Elaborado pela autora, com base na pesquisa realizada.

Nos dados organizados no gráfico 3, em relação às aplicadas no âmbito profissional, o Scrum aparece como mais trabalhado nos projetos. Para otimizar o Projeto E com agilidade e o Scrum com qualidade, podem ser trabalhadas as metodologias juntas onde a complexidade de entendimento se una com a aplicação de agilidade. O Projeto $\mathrm{E}$ possui um grau de dificuldade maior no quesito de gerenciamento. Muitas são as etapas para aprender e aplicar no mercado de trabalho, que exige muito em pouco tempo.

A agilidade que o Scrum possui já veio lapidada desde sua construção, apesar de sua falta de etapas bem esclarecidas, em relação ao desenvolvimento de projetos de web design, deixa o gerente de projetos a par de criar seu próprio caminho para extrair o projeto dos stakeholders com organização pré-estabelecida do Scrum, estrutura essa em que os dados expostos na entrevista e no gráfico 3 comprovam sua eficácia. 
Gráfico 3 - técnicas estudadas na academia e utilizadas no mercado de trabalho

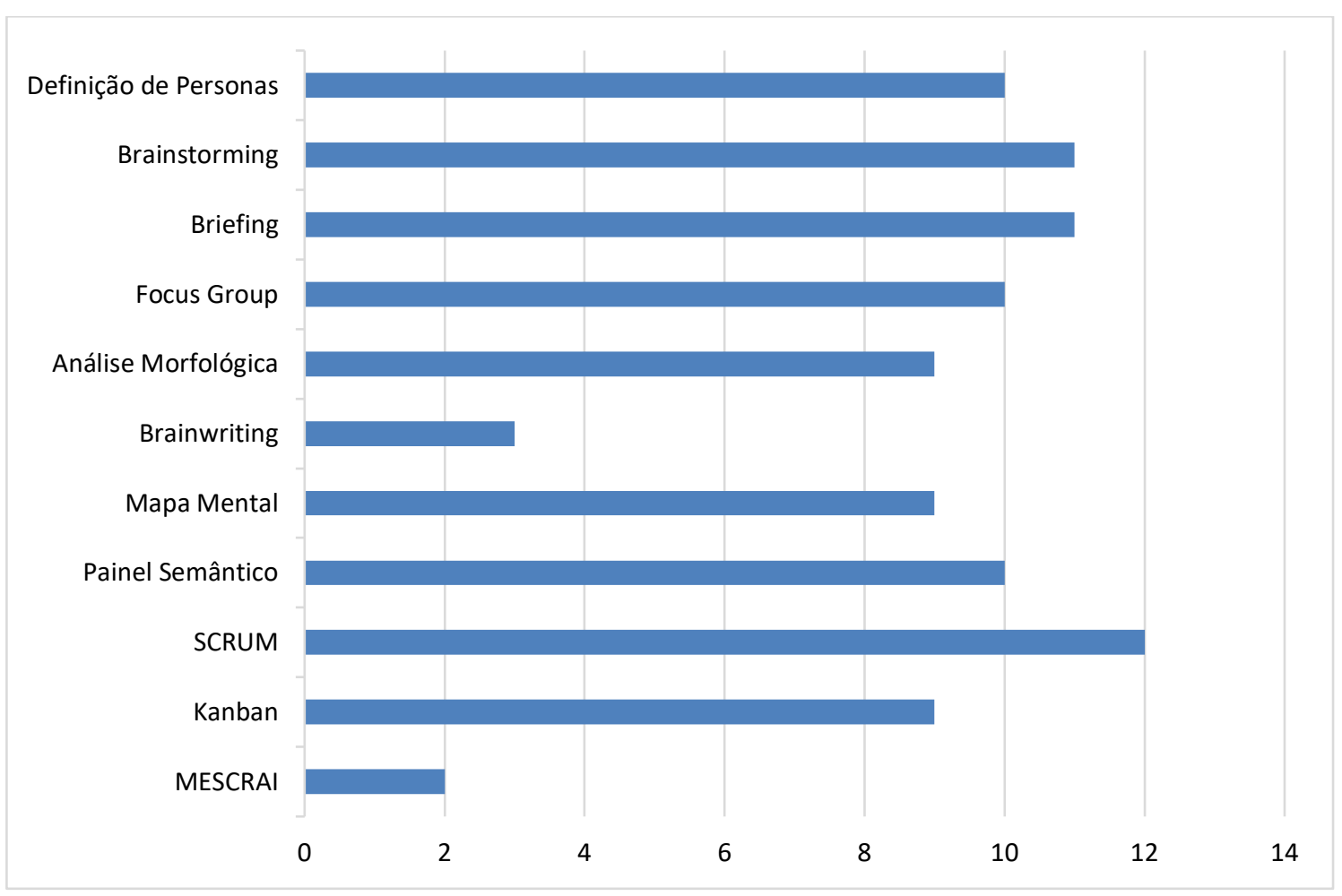

Fonte: Elaborado pela autora, com base na pesquisa realizada.

\subsection{PROJETO E - SCRUM}

Ao unificar as metodologias Projeto E e Scrum, sugere-se a nomenclatuta Projeto E - Scrum, que seria desenvolver a primeira através da segunda, como explica-se a seguir:

A proposta se faz na categorização das etapas do Projeto E considerado como sprints do projeto. Os membros do projeto serão determinados como no Scrum, onde haverá o Scrum Master, Product Owner e o Time Scrum. Todos devem acompanhar as etapas do Projeto E que serão consideradas sprints. A etapa de estratégia deve seguir a regra de inicialmente ter uma reunião de planejamento de entrega como todos os envolvidos do projeto. Ao iniciar alguma etapa do Projeto $E$ deve-se organizar uma reunião de planejamento da sprint para estabelecer as responsabilidades e esclarecer ao time questões como a duração de cada tarefa.

Como podemos observar na tabela 1 as etapas do Projeto E são subdivididas em outros processos que devem seguir uma reunião diária de sprints para acompanhar o andamento e apresentar o backlog para o time. 
Tabela 1 - Comparação das Metodologias Projeto E e Scrum

\begin{tabular}{|c|c|}
\hline PROJETO E & SCRUM \\
\hline \multicolumn{2}{|c|}{ Características } \\
\hline $\begin{array}{l}\text { Definir com clareza e objetividade uma metodologia } \\
\text { projetual; } \\
\text { Foca na usabilidade e processos específicos do Web } \\
\text { Design; }\end{array}$ & $\begin{array}{l}\text { Projeto é visível a todos; } \\
\text { Utilizado em projetos de software e Websites; } \\
\text { Cliente faz parte do time; }\end{array}$ \\
\hline \multicolumn{2}{|c|}{ Pontos em comum } \\
\hline \multicolumn{2}{|c|}{$\begin{array}{l}\text { Permite alteração de ordem de etapas; } \\
\text { Adaptável à complexidade de projetos; } \\
\text { Permite alteração de funções do agente; } \\
\text { Difícil de dominar. }\end{array}$} \\
\hline \multicolumn{2}{|c|}{ Diferenças } \\
\hline $\begin{array}{l}\text { Omitir etapas; } \\
\text { Não inclui mais etapas. }\end{array}$ & $\begin{array}{l}\text { Todas as etapas devem ser executadas; } \\
\text { Pode-se empregar mais técnicas; }\end{array}$ \\
\hline \multicolumn{2}{|c|}{ Pontos positivos } \\
\hline $\begin{array}{l}\text { Boa descrição das etapas; } \\
\text { Foco na experiência do usuário; }\end{array}$ & $\begin{array}{l}\text { Agilidade; } \\
\text { Motivação; } \\
\text { Funcionalidades com valor em primeiro lugar; }\end{array}$ \\
\hline \multicolumn{2}{|c|}{ Pontos Negativos } \\
\hline Dificuldade para gerenciar as etapas; & $\begin{array}{l}\text { Falta de planejamento do escopo; } \\
\text { Muito foco no desenvolvimento do projeto sem } \\
\text { conceitos de usabilidade; }\end{array}$ \\
\hline
\end{tabular}

Fonte: Elaborado pela autora, com base na pesquisa realizada.

Ao término de cada etapa será realizada a revisão da sprint em que todos participam para fazer alterações ou ressaltar alguns pontos em que a etapa em desenvolvimento possa melhorar. Antes de passar para a próxima etapa se fará a retrospectiva da sprint anterior para destacar questões em que possam melhorar o desenvolvimento na próxima Sprint conforme figura 2: 

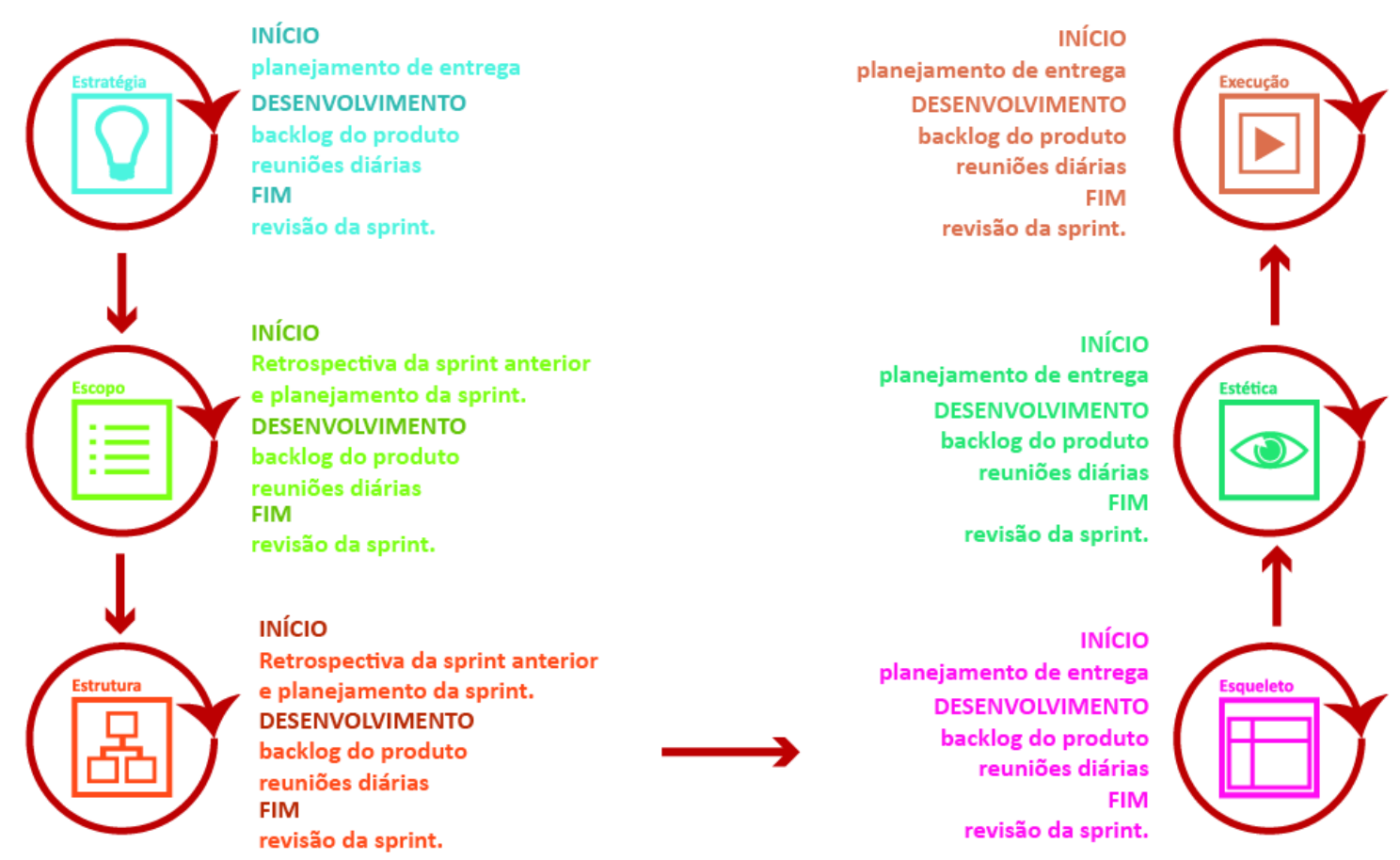

Figura 2 - Unificação das Metodologias Projeto E e Scrum

Fonte: Elaborado pela autora, com base na pesquisa realizada.

\section{CONSIDERAÇÕES FINAIS}

O objetivo deste artigo foi propor a unificação das metodologias Projeto E e Scrum no meio dos projetos de Web Design para otimizar os processos dentro do âmbito profissional. Como apresentado, estas metodologias possuem muito em comum, mas há oportunidade de se complementarem e possibilitar mais agilidade no processo das etapas que o Projeto E apresenta com uma minuciosa descrição e com o seu foco na experiência do usuário.

O que abre portas para um estudo mais avançado de novas tecnologias que englobam a responsividade (acesso das mídias virtuais por todos os dispositivos existentes) e a acessibilidade (compatibilidade com dispositivos que auxiliam pessoas com deficiência visual, auditiva e motora) dentro desses projetos.

Entretanto se faz necessário o teste das etapas das metodologias para saber sua eficácia dentro de um projeto de Design Web. Campo este que está a cada dia mais crescendo e precisando de auxílio para fornecer aos clientes projetos que satisfaçam toda a gama de diversidade de usuários que possuímos atualmente.

As metodologias precisam estar em constante mutação para que estejam ao alcance das tecnologias que estão sendo desenvolvidas a fim de serem ágeis e eficazes na esfera dígito-virtual.

Sugere-se aos acadêmicos que, por ventura terão acesso a este, utilizem dados a fim de alcançarem voos maiores, quer seja concordando ou discordando da proposta original. Afinal, design é resolução de problemas. Aos docentes da área, sugere-se a ousadia no apoio em testar o Projeto E - Scrum visando a sua veracidade. Aos profissionais da área, desafiamos experimenta-lo. 


\section{REFERÊNCIAS}

CRUZ, Fábio. Scrum e Guia PMBOK unidos no gerenciamento de projetos. Rio de Janeiro: Brasport, 2013.

FARAH, Suraia Felipe. Considerações Sobre Metodologias de Projeto em Design em Pelos Caminhos do Design: metodologia de projeto. Londrina: EDUEL, 2012.

FONTOURA, Antônio Martiniano. Um pouco de História em Pelos Caminhos do Design: metodologia de projeto. Londrina: EDUEL, 2012.

GUERRATO, Dani. Desenvolvimento ágil utilizando Scrum, 2013. Disponível em: $<$ http://tableless.com.br/desenvolvimento-agil-utilizando-scrum/>. Acesso em: 6 jun. 2015.

GOMES FILHO, João. Design do objeto: bases conceituais. São Paulo: Escrituras. Editora, 2006.

LINDEN, J.; LACERDA, A. Metodologia projetual em tempos de complexidade em design em pelos caminhos do design: metodologia de projeto. Londrina: EDUEL, 2012. MEURER, H.; SZABLUK, D. Projeto E - Metodologia Projetual como Modelo de Aprendizagem Baseada em Projetos. 2011. Disponível em: <http://projetoe.com/>. Acesso em: 6 jun. 2015.

MEURER, H.; SZABLUK, D. Projeto E: metodologia projetual para ambientes dígitovirtuais em design em pelos caminhos do design: metodologia de projeto. Londrina: EDUEL,2012.

NIEMEYER, L. Design no Brasil: origens e instalação. 3a Ed. Rio de Janeiro: 2AB, 2000. SCHNEIDER, Beat. Design - uma introdução: o design no contexto social, cultural e econômico. São Paulo: Editora Blücher, 2010.

SCHWABER, Ken. Guia do Scrum. Scrum Alliance, 2009. Disponível em: < http://www.trainning.com.br/download/GUIA_DO_SCRUM.pdf> Acesso em: 6 de jun. 2015. 